\title{
Amadurecimento de manga 'Ubá’ com etileno e carbureto de cálcio na pós-colheita
}

\author{
Ripening of 'Ubá' mango using ethylene and calcium carbide
}

\section{Danielle Fabíola Pereira da Silva ${ }^{\mathrm{I}}$ Luiz Carlos Chamhum Salomão ${ }^{\mathrm{II}}$ Dalmo Lopes Siqueira ${ }^{\mathrm{II}}$ Paulo Roberto Cecon"II Tiago Barbosa Struiving ${ }^{\mathrm{II}}$}

\section{RESUMO}

Mangas 'Ubá' fisiologicamente maduras foram tratadas com etileno ou carbureto de cálcio $\left(\mathrm{CaC}_{2}\right)$ visando à antecipação e à uniformização do amadurecimento. Frutos com massa média de $133,8 \pm 1,9 \mathrm{~g}$ foram expostos às doses de 0 , 20, 40, 80 e $160 \mathrm{~g}$ de $\mathrm{CaC}_{2} \mathrm{~m}^{-3}$ de câmara ou 0, 50, 100, 200 e $400 \mathrm{~mL}$ de etileno $\mathrm{m}^{-3}$ de câmara durante $24 \mathrm{~h}$, em câmaras a $18,1 \pm 0,7^{\circ} \mathrm{C}$ e $90 \pm 3 \%$ de UR. Após o tratamento, os frutos permaneceram sob as mesmas condições de temperatura e UR, e foram avaliados aos 0, 1, 3, 6, 9, 12 e 15 dias de armazenamento. $\mathrm{O}$ etileno e o $\mathrm{CaC}_{2}$ acentuaram a perda de massa das mangas. Nos frutos tratados com $\mathrm{CaC}_{2}$, o pico climatérico respiratório ocorreu aos 3, 6, 9, 9 e 12 dias de armazenamento para as doses 160, 80, 40, $20 \mathrm{e} 0 \mathrm{~g} / \mathrm{m}^{3}$, respectivamente. Nos frutos tratados com etileno, este pico foi registrado aos 3, 3, 6, 6 e 12 dias de armazenamento para as doses 400, 200, 100, 50 e 0mL m $\mathrm{m}^{-3}$, respectivamente. Todas as doses de $\mathrm{CaC}_{2}$ e de etileno aceleraram a perda de firmeza, o aumento do teor de sólidos solúveis e de carotenóides, a redução da acidez e a mudança de cor da casca e da polpa dos frutos. Por outro lado, esses produtos também acentuaram a perda de eletrólitos celulares e de ácido ascórbico. Nos frutos tratados com etileno, a queda da firmeza foi mais brusca em relação aos tratados com $\mathrm{CaC}_{2}$. No entanto, o extravasamento de solutos foi maior para frutos tratados com $\mathrm{CaC}_{2}$. O aumento no teor de sólidos solúveis foi proporcional ao aumento das doses de $\mathrm{CaC}_{2}$ e de etileno. Doses de $20 \mathrm{~g}$ de $\mathrm{CaC}_{2}$ e $50 \mathrm{~mL}$ de etileno por $\mathrm{m}^{3}$ de câmara foram suficientes para antecipar e uniformizar o amadurecimento de manga 'Ubá'.

Palavras-chave: Mangifera indic,a L., climatização, acetileno, qualidade do fruto.

\section{ABSTRACT}

Physiologically mature 'Ubá' mangoes were treated with ethylene or calcium carbide $\left(\mathrm{CaC}_{2}\right)$ aiming to accelerate and standardize fruit ripening. Fruits with mean weight of $133.8 \pm 1.9 \mathrm{~g}$ were treated with concentrations of 0 , 20, 40, 80 and $160 \mathrm{~g} \mathrm{CaC}_{2}$ chamber $\mathrm{m}^{-3}$ and 0, 50, 100, 200 and $400 \mathrm{~mL}$ of ethylene/chamber $\mathrm{m}^{3}$, in chambers at $18.1 \pm 0.7^{\circ} \mathrm{C}$ and $90 \pm 3 \% \mathrm{RH}$, for $24 \mathrm{~h}$. After the treatment, the fruits were kept under the same conditions of temperature and $\mathrm{RH}$, and were evaluated at 0, 1, 3, 6, 9, 12 and 15 days of storage. Ethylene and $\mathrm{CaC}_{2}$ increased mass loss of the fruits. Mangoes treated with $\mathrm{CaC}_{2}$ showed the respiratory climacteric peak at 3, 6, 9, 9 and 12 days of storage for the concentrations 160, 80, 40, 20 and $0 \mathrm{~g} \mathrm{~m}^{-3}$, respectively. Fruits treated with ethylene showed the peak at 3, 3, 6, 6 and 12 days of storage for the concentrations 400, 200, 100, 50 and $0 \mathrm{~mL} \mathrm{~m} \mathrm{~m}^{-3}$, respectively. All concentrations of $\mathrm{CaC}_{2}$ and ethylene accelerated the loss of firmness, the increase of soluble solids and carotenoids, the reduction of acidity and the change in color of skin and pulp. However, these products also increased electrolyte leakage and decreased ascorbic acid content. Fruits treated with ethylene showed sharper firmness loss compared with fruits treated with $\mathrm{CaC}_{2}$. On the other hand, solute leakage was higher in fruits treated with $\mathrm{CaC}_{2}$. Soluble solids content increased with increasing concentrations of $\mathrm{CaC}_{2}$ and ethylene. The concentrations of $20 \mathrm{~g}$ of $\mathrm{CaC}_{2}$ and $50 \mathrm{~mL}$ of ethylene per chamber $\mathrm{m}^{3}$ were sufficient to accelerate and uniformize ripening of 'Ubá' mango.

Key words: Mangifera indica L., climatization, acetylene, fruit quality.

\section{INTRODUÇÃO}

No Brasil, a mangueira é cultivada em quase todas as regiões, havendo potencial de expansão tanto da área cultivada quanto da produtividade (MENDONÇA et al., 2003). Em Minas Gerais,

IUniversidade Federal de Viçosa (UFV), Av. P.H. Rolfs, s/n, 69908-970, Viçosa, MG, Brasil. E-mail: danieele@ufv.br. Autor para correspondência.

IIDepartamento de Fitotecnia, UFV, Viçosa, MG, Brasil. 
especificamente na Zona da Mata Mineira, destaca-se a cultivar Ubá, que é encontrada crescendo espontaneamente em praticamente todos os municípios da região. Os frutos dessa cultivar são utilizados principalmente no processamento industrial, mas têm grande aceitação para o consumo in natura (ROCHA et al., 2011).

A manga é um fruto climatérico que sofre incremento na respiração e na produção de etileno quando exposta à aplicação exógena de etileno (SILVA et al., 2011). Esse hormônio antecipa significativamente o tempo requerido para o pico climatérico (STEFFENS et al., 2006), principalmente quando aplicado antes dessa fase (FIORAVANÇO et al., 2007). O efeito do etileno produzido naturalmente pelas plantas pode ser substituído pelo suprimento exógeno para iniciar a respiração climatérica e desencadear o amadurecimento (NOGUEIRA et al., 2007), já que ambos induzem o processo de autocatálise da síntese deste hormônio pelos frutos (SANTOS et al., 2005).

Comercialmente, é bastante difundido o uso do etileno gasoso na indução do amadurecimento ou climatização de frutos, o qual é adquirido na forma de gás comprimido, em mistura com nitrogênio (SILVA et al., 2009a). A climatização também pode ser feita com acetileno, um análogo do etileno gerado a partir da queima do carbureto de cálcio $\left(\mathrm{CaC}_{2}\right)$, e que vem sendo utilizado por pequenos e médios produtores rurais como alternativa ao etileno gasoso (ZEITSCHRIFTEN, 2009).

Foram avaliados os efeitos da climatização em manga 'Nam Dokmai', 'Kaew' e 'Chok Anan' com carbureto de cálcio na dose de $10 \mathrm{~g} \mathrm{CaC}_{2} \mathrm{~kg}^{-1}$ de frutos e ethephon na dose de $200 \mathrm{mg} \mathrm{L}^{-1}$ durante 18 horas de exposição em câmaras de alvenaria. Após os tratamentos, os frutos foram armazenados a $24 \pm 2^{\circ} \mathrm{C} \mathrm{e}$ $33 \pm 2^{\circ} \mathrm{C}$ durante sete dias nas condições ambiente da Índia. Observou-se que o carbureto de cálcio e o ethephon anteciparam as mudanças e uniformizaram as características de cor da casca e da polpa, o teor de sólidos solúveis e a firmeza da polpa (ZEITSCHRIFTEN, 2009).

A manga 'Ubá' geralmente amadurece de novembro a janeiro, a maturação desuniforme em uma mesma planta exige colheita escalonada, que pode prolongar-se por até um mês (SILVA et al., 2011). Frutos fisiologicamente maduros de diversas espécies e cultivares têm sido submetidos a tratamentos com etileno ou seus análogos tanto na pré quanto na póscolheita, tanto em nível experimental como comercial, visando a acelerar e uniformizar o seu amadurecimento e, ou, melhorar o seu padrão de qualidade.
A resposta dos frutos ao tratamento com etileno e seus análogos depende da sensibilidade do tecido, da concentração utilizada, da composição da atmosfera, do tempo de exposição, da temperatura e da sensibilidade da espécie ou cultivar. Dessa forma, o objetivo deste trabalho foi comparar os efeitos de diferentes doses de etileno gasoso e carbureto de cálcio na antecipação e uniformização do amadurecimento na pós-colheita de manga 'Ubá'.

\section{MATERIAL E MÉTODOS}

Os frutos de mangueira 'Ubá' fisiologicamente maduros foram colhidos em 11 de dezembro de 2008 na Fazenda Experimental Sementeira, localizada em Visconde do Rio Branco, MG (latitude de $21^{\circ} 00^{\prime} 37^{\prime}$ 'S, longitude de 42 50 ' $26^{\prime}$ 'O e altitude de $352 \mathrm{~m}$ ), pertencente à Universidade Federal de Viçosa, em pomar com cerca de 30 anos de idade. Após a colheita, os frutos foram transportados em caixas plásticas para o Laboratório de Análise de Frutas do Setor de Fruticultura do Departamento de Fitotecnia da UFV.

No laboratório, foi efetuada nova seleção e padronização dos frutos, lavagem em solução aquosa de detergente $0,2 \%$ e tratamento com solução de fungicida Prochloraz (Sportak $450 \mathrm{CE}$, da empresa Hoechst Schering AgrEvo UK Ltd. - Inglaterra), na dose de $49,5 \mathrm{~g} 100 \mathrm{~L}^{-1}$ de água, por $5 \mathrm{~min}$, e secagem ao ar. Posteriormente, parte dos frutos foi tratada com carbureto de cálcio nas doses de 0,20,40, 80 e 160 $\mathrm{g} \mathrm{m}^{-3}$ de câmara durante $24 \mathrm{~h}$ de exposição; a outra parte dos frutos foi tratada com etileno gasoso nas concentrações de $0,50,100,200$ e $400 \mathrm{~mL} \mathrm{~m}^{-3}$ durante $24 \mathrm{~h}$ de exposição. A seguir, foram armazenados a $18,1 \pm 0,7^{\circ} \mathrm{C}$ e analisados nos tempos $0,1,3,6,9,12$ e 15 dias, sendo o dia zero o dia a colheita dos frutos. Para o tratamento com etileno e $\mathrm{CaC}_{2}$, os frutos foram acondicionados em caixas plásticas de 32,25L recobertas com filme de polietileno de baixa densidade $(89 \mathrm{~cm}$ altura $\times 59 \mathrm{~cm}$ de largura, $30 \mu \mathrm{m}$ de espessura; permeabilidade: $70 \mathrm{TPO}_{2}, 290 \mathrm{TPCO}_{2} \mathrm{e}$ $<0,01 \mathrm{TPH}_{2} \mathrm{O}$ sem perfuração), em câmara fria a $18,1 \pm 0,7^{\circ} \mathrm{C}$.

Os experimentos foram instalados segundo um esquema de parcelas subdivididas, tendo nas parcelas as concentrações (cinco níveis) e nas subparcelas os dias de avaliação (sete níveis) no delineamento inteiramente casualizado, com três repetições e três frutos por unidade experimental.

Os frutos foram submetidos às seguintes análises: produção de $\mathrm{CO}_{2}$ (cromatografia gasosa), perda de massa fresca (gravimetria), coloração da casca (colorímetro digital), consistência da polpa (penetrômetro digital com ponteira de $12 \mathrm{~mm}$ ), 
extravasamento de solutos (de acordo com metodologia de SEREK et al. (1995)), acidez titulável (titulação com $\mathrm{NaOH}$ e os resultados expressos em \% de ácido cítrico), vitamina $C$ (titulação com reagente de Tillman 2,6 diclorofenolindofenol) e teor de sólidos solúveis (refratômetro digital).

Para a análise dos dados das variáveis, foi feito o desdobramento, independentemente de a interação ser significativa ou não, e as médias dos fatores foram submetidas à análise de regressão. A escolha das equações foi feita baseando-se na significância dos coeficientes de regressão pelo teste " $t$ " (Student), no coeficiente de determinação $\left(\mathrm{R}^{2}\right)$ e no potencial para explicar o fenômeno biológico.

\section{RESULTADOS E DISCUSSÃO}

Em frutos tratados com carbureto de cálcio, o pico respiratório ocorreu aos 3, 6, 9, 9 e 12 dias de armazenamento para as doses 160, 80, 40, 20 e $0 \mathrm{~g} \mathrm{~m}^{-3}$, respectivamente (Figura $1 \mathrm{~A}$ ). Nos frutos tratados com etileno, o climatérico respiratório foi registrado aos 3 , 3, 6, 6 e 12 dias de armazenamento para as doses 400,

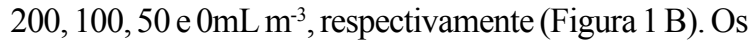
maiores picos foram observados para frutos tratados com $400 \mathrm{~mL} \mathrm{~m}^{-3}$ de etileno $\left(243,08 \mathrm{mg} \mathrm{kg}^{-1} \mathrm{~h}^{-1}\right)$ e com $160 \mathrm{~g} \mathrm{~m}^{-3}$ de carbureto de cálcio $\left(212,77 \mathrm{mg} \mathrm{kg}^{-1} \mathrm{~h}^{-1}\right)$. Isso indica que o etileno nas doses de 200 e $400 \mathrm{~mL} \mathrm{~m}^{-3}$ e o $\mathrm{CaC}_{2}$ na dose de $160 \mathrm{~g} \mathrm{~m}^{-3}$ foi mais eficaz na antecipação do climatério, não diferindo estatisticamente entre si. Para ambos os produtos, doses mais elevadas ampliaram a diferença de produção de $\mathrm{CO}_{2}$ entre o mínimo e o máximo climatérico. Maiores doses podem ter sido mais eficientes, possivelmente pela maior difusão do produto para o interior dos tecidos. De acordo com a figura 1, é possível observar que a taxa respiratória aumentou temporariamente e o completo amadurecimento ocorreu após o pico respiratório. De acordo com TAIZ \& ZEIGER (2006), o climatério respiratório ocorre sob intensa atividade metabólica, com predominância de reações oxidativas. A energia liberada é reutilizada, em diferentes etapas, para
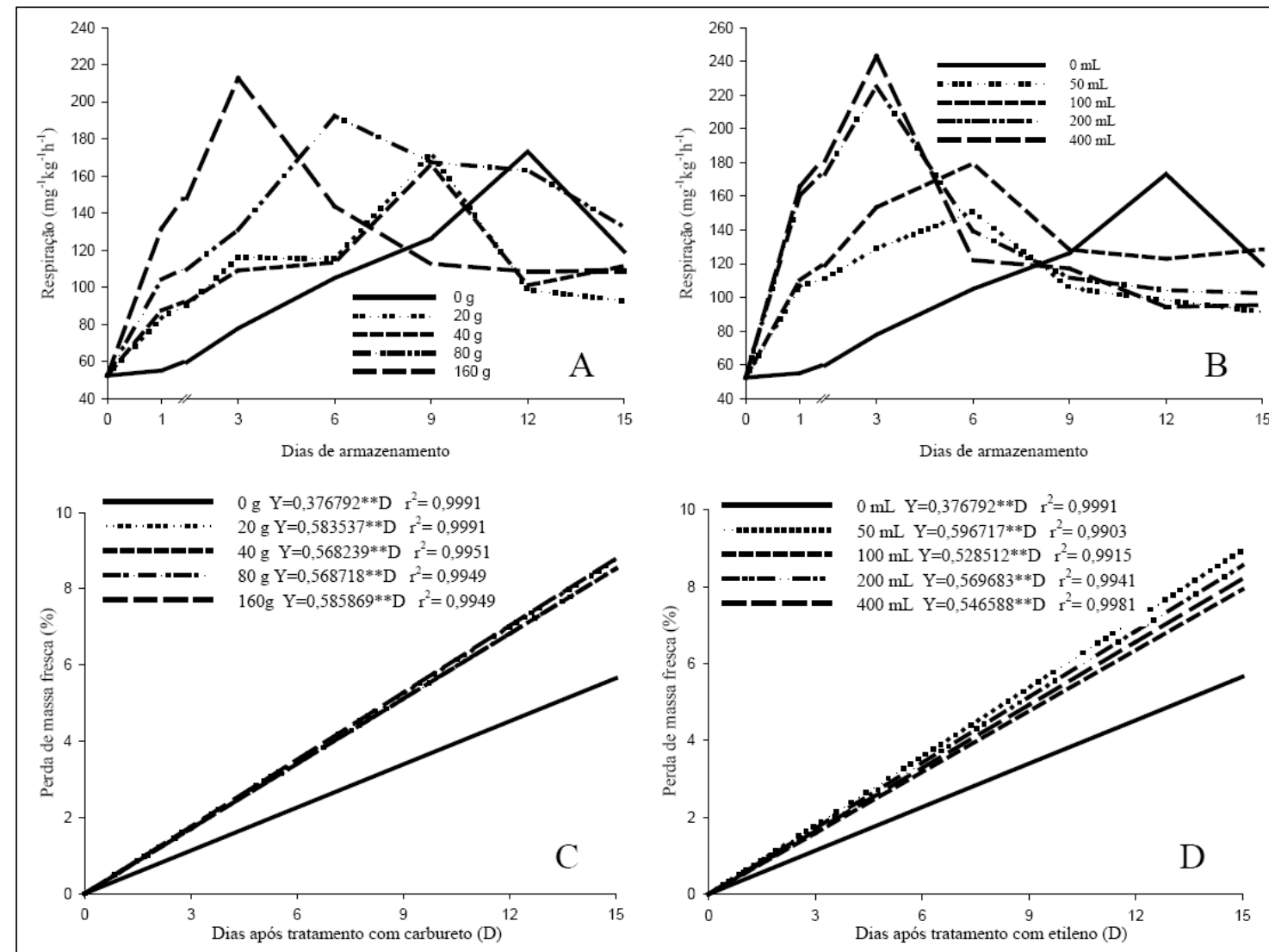

Figura 1 - Produção de $\mathrm{CO}_{2}\left(\mathrm{mg} \mathrm{kg}^{-1} \mathrm{~h}^{-1}\right)$ de manga 'Ubá' tratada com carbureto de cálcio (A) e etileno (B) e estimativa da perda de massa fresca (\%) de manga 'Ubá' tratada com carbureto de cálcio (C) e etileno (D).

Ciência Rural, v.42, n.2, fev, 2012. 
produção de compostos intermediários, requeridos para a síntese de numerosas substâncias químicas, que se formam a partir do climatério respiratório, até o completo amadurecimento do fruto. O pico de respiração designado como máximo climatérico foi seguido por um período de declínio na atividade, designado como estádio pós-climatérico.

A perda de massa fresca dos frutos de todos os tratamentos com carbureto de cálcio e etileno (Figura 1C e 1D) aumentou linearmente durante o armazenamento. Segundo SILVA et al. (2009a), a perda de massa fresca é um sintoma inicial de perda de água. Os tratamentos $0 \mathrm{~g} / \mathrm{m}^{3}$ de $\mathrm{CaC}_{3}$ e $0 \mathrm{~mL} \mathrm{~m}^{-3}$ de etileno determinaram menor perda de massa à manga durante todo o período experimental, chegando no $15^{\circ}$ dia com perda acumulada de 5,7\% de massa fresca.

Não se encontrou, na literatura consultada, referência ao limite de perda de massa tolerado para manga. Nas condições deste experimento, as maiores perdas situaram-se entre $8,8 \%$ e $9 \%$ no $15^{\circ}$ dia de armazenamento (Figura 1C e 1D). De acordo com CHITARRA\& CHITARRA(2005), perdas para produtos hortícolas da ordem de 3 a $6 \%$ são suficientes para causar um marcante declínio na qualidade, mas alguns produtos são ainda comercializáveis com $10 \%$ de perda de umidade.

A mudança característica inicial do amadurecimento é a degradação da clorofila, bem como a síntese de outros pigmentos. A mudança de cor da casca foi bem pronunciada para frutos tratados com carbureto de cálcio (Figura 2A e 2B). Observa-se, nesses frutos, que a mudança da cor da casca de verde para amarelo ocorreu gradualmente durante o armazenamento para as doses 20,40, 80 e $160 \mathrm{~g} \mathrm{~m}^{-3} \mathrm{de}$ $\mathrm{CaC}_{2}$. Esses mesmos frutos apresentaram coloração amarelo intenso aos doze dias de armazenamento, com $\mathrm{h}=85,62^{\circ} ; 82,11^{\circ} ; 78,73^{\circ}$ e $79,03^{\circ}$, respectivamente, enquanto a testemunha apresentou $\mathrm{h}=90,43$. Em frutos tratados com etileno, a mudança de cor da casca foi mais lenta em relação ao $\mathrm{CaC}_{2}$, notando-se um tom amarelo na casca a partir de doze dias de armazenamento (Figura 2 B), com valores de h de 87,29 $; 89,27^{\circ} ; 85,24^{\circ}$ e $88,63^{\circ}$ para as doses $50,100,200$ e $400 \mathrm{~mL} \mathrm{~m}^{-3}$ de etileno, respectivamente, após doze dias.

A consistência da polpa apresentou queda em torno de $40 \%$ do dia zero para o primeiro dia para frutos tratados com carbureto de cálcio (Figura 2C), enquanto que para frutos não-tratados a queda foi de apenas $26 \%$. Todavia, para frutos tratados com etileno (Figura 2D), a queda registrada entre o dia zero e o primeiro dia foi em torno de $64 \%$, indicando que o etileno foi mais eficiente que o carbureto de cálcio na redução da consistência no período mencionado.
Resultados contrários foram obtidos por CHITARRA \& CHITARRA(2005), em que frutos de manga 'Tommy Atkins' tratados com $50 \mathrm{~g} \mathrm{~m}^{-3} \mathrm{CaC}_{2}$ apresentaram maior maciez da polpa em relação aos frutos tratados com $150 \mathrm{~mL} \mathrm{~m}^{-3}$ de etileno em temperatura ambiente. No presente trabalho, observou-se, no entanto, comportamento diferente, o que pode ser explicado pelo controle das temperaturas durante o tratamento e o armazenamento. Essa menor redução da firmeza indica um potencial do carbureto para antecipar e uniformizar o amadurecimento em manga, desde que haja controle da temperatura durante o tratamento e armazenamento.

Houve maior extravasamento de eletrólitos para frutos tratados com 160 e $80 \mathrm{~g}$ de carbureto de cálcio, respectivamente (Figura $2 \mathrm{E}$ e $2 \mathrm{~F}$ ), demonstrando que as maiores doses de $\mathrm{CaC}_{2}$ causaram maior desorganização das membranas celulares e, consequentemente, maior antecipação do amadurecimento, conforme observado para a produção de $\mathrm{CO}_{2}$ (Figura 1A).

Frutos tratados com etileno tiveram extravasamento de solutos menor (Figura $2 \mathrm{~F}$ ), quando comparados com frutos tratados com $\mathrm{CaC}_{2}$ (Figura 2 E). Observa-se, nas figuras $2 \mathrm{E} \mathrm{e} 2 \mathrm{~F}$, que, quanto maior a dose, maior foi o extravasamento durante todo o período experimental.

A acidez titulável teve queda acentuada já no terceiro dia de armazenamento, tanto para frutos tratados com carbureto de cálcio (Figura 3A), como para frutos tratados com etileno (Figura 3B). Para frutos não tratados, observa-se queda lenta e acentuada da acidez titulável, o que confirma o potencial do etileno e/ou seus análogos em antecipar e uniformizar o amadurecimento de manga. Foi possível observar que a redução nos teores de acidez teve comportamento semelhante para os produtos testados, o que confirma relatos feitos por SILVA et al. (2009b) de que, após a colheita e durante o armazenamento, a concentração dos ácidos orgânicos usualmente declina em decorrência de sua utilização como substrato na respiração ou da sua transformação em açúcares. Essas transformações têm papel importante nas características de sabor (acidez) e do aroma, uma vez que alguns compostos são voláteis.

Observa-se queda gradual para vitamina $\mathrm{C}$ em frutos tratados com carbureto de cálcio durante todo o período de armazenamento (Figura 3C e 3D). Todavia, para frutos tratados com etileno, a queda foi brusca até o terceiro dia de armazenamento e, a partir daí, gradual (Figura 3D). A queda abrupta para frutos tratados com etileno é indesejável, pois indica perda do valor nutritivo do fruto. Ao final do período de avaliação, tanto frutos tratados $\operatorname{com} \mathrm{CaC}_{2}$ quanto frutos 


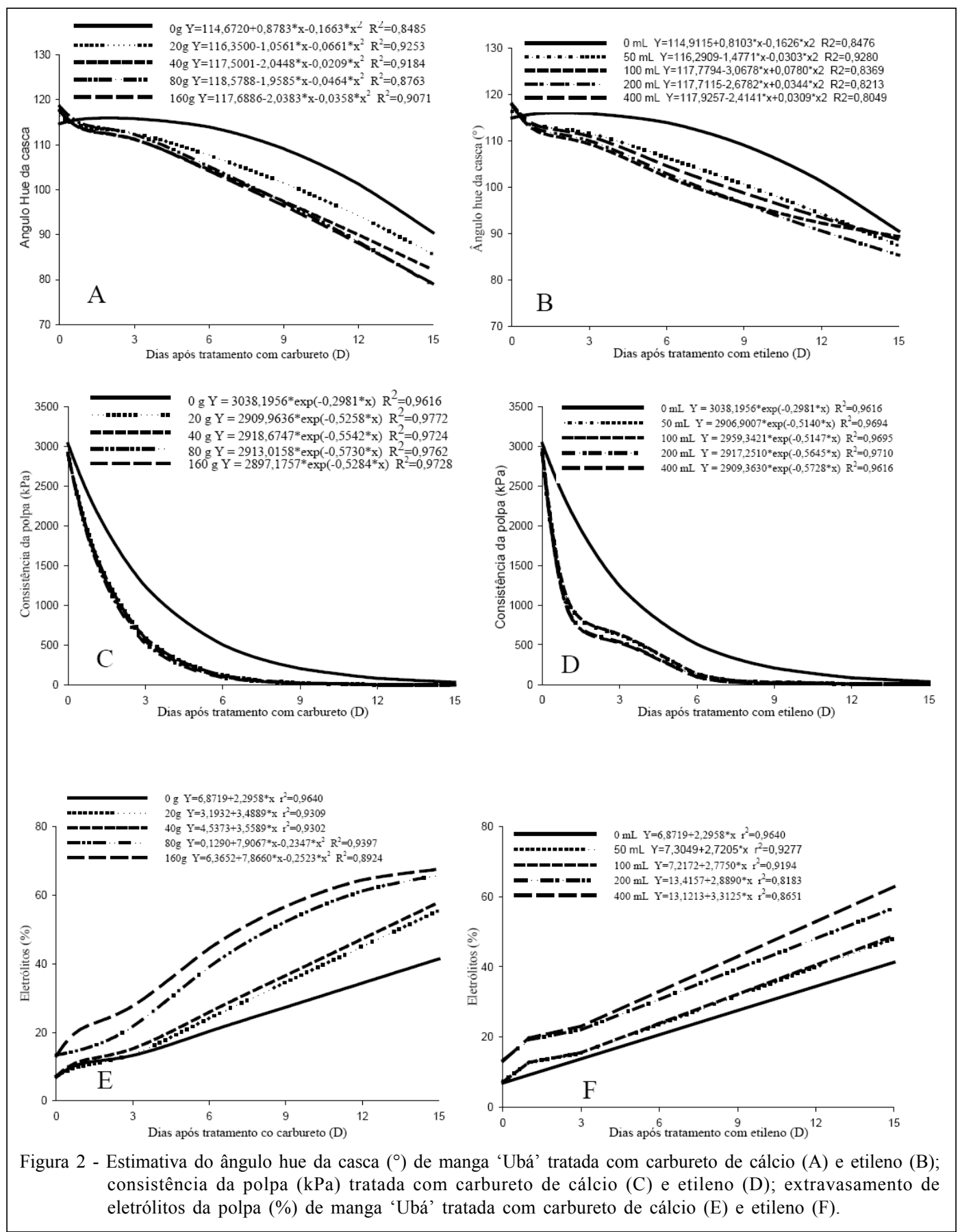

tratados com etileno aos quinze dias de armazenamento apresentaram teor de vitamina C em torno de $40 \mathrm{mg} .100 \mathrm{~g}^{-1}$ de polpa, enquanto que, para frutos não tratados, o teor de vitamina $\mathrm{C}$ para o mesmo período foi em torno

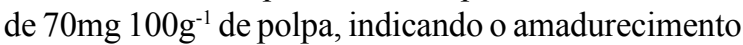
desuniforme dos frutos não-tratados. PAL (1998) trabalhando com manga 'Rataul', com ethephon nas doses 500,1000 e $1500 \mathrm{~mL}^{-1}$ e carbureto de cálcio $(25 \mathrm{~g}$ $10 \mathrm{~kg}^{-1}$ de fruto), observou que frutos tratados com ethephon tiveram a maior perda de peso de massa fresca em relação aos frutos tratados com $\mathrm{CaC}_{2} \mathrm{e}$ do tratamento controle e os frutos tratados com $\mathrm{CaC}_{2}$ tiveram maior percentual de apodrecimento e menor conteúdo de vitamina $\mathrm{C}$ ao final do período avaliado. HOJO et al. (2011) explicaram que, durante a senescência, o ácido ascórbico do fruto é utilizado em reações oxidativas, que são ativadas pelos estresses sofridos pelas membranas celulares durante este período. 


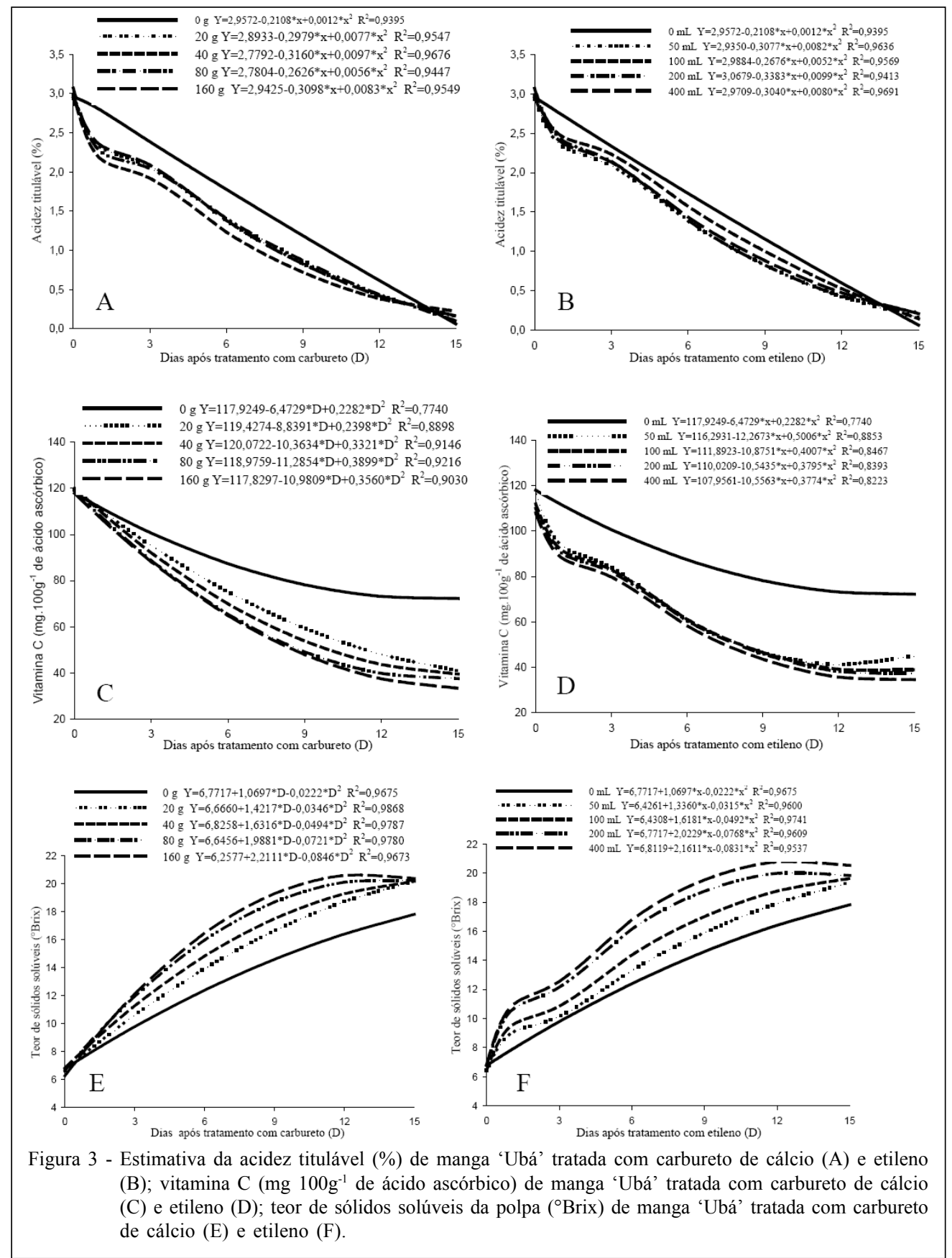

O teor de sólidos solúveis foi crescente durante todo o período de avaliação, sendo que, quanto maior a dose de carbureto ou etileno, maiores foram os teores atingidos (Figura 3E e 3F). Os tratamentos com $\mathrm{CaC}_{2}$ e etileno provocaram aumento no teor de sólidos solúveis totais dos frutos, comprovando que este produto pode ser utilizado para amadurecer os frutos fora da planta com possível aumento no rendimento industrial. Para frutos tratados com carbureto de cálcio (Figura 3E), o teor de SS de $11^{\circ}$ Brix foi alcançado a partir do terceiro dia somente para as doses 40, 80 e $160 \mathrm{~g} \mathrm{~m}^{-3}$. BRAZ et al. (2008), trabalhando com indução do amadurecimento de mangas 'Ubá' 'Tommy Atkins', com a aplicação pós-colheita de ethephon na dose de $1000 \mathrm{~mL}^{-1}$, mantidas à temperatura ambiente, também observaram que, para frutos tratados, o teor de $11^{\circ}$ Brix só foi atingido no terceiro dia após aplicação de ethephon.

O início do climatério em manga foi caracterizado por intensa degradação de clorofila da 
casca, indicado pela queda do valor de h (Figura $2 \mathrm{~A}$ e 2B). Simultaneamente, a polpa apresentou aumento na concentração de sólidos solúveis (Figura 3E e 3F) e redução acentuada da acidez titulável (Figura 3A e 3B) e da consistência (Figura 2C e 2D). De acordo com TAIZ \& ZEIGER (2006), os frutos têm vida independente e utilizam, para tal, suas próprias reservas de substratos, acumulados durante o seu crescimento e maturação, com consequente depressão progressiva nas reservas de matéria seca acumulada. Deve-se salientar que as atividades não são apenas catabólicas. Alguns órgãos vegetais utilizam a energia liberada pela respiração para continuar a síntese de pigmentos, enzimas e outros materiais de estrutura molecular elaborada, tão logo eles são destacados da planta. Essas sínteses são parte essencial do processo de amadurecimento de muitos frutos, como, por exemplo, a manga.

Tanto nos frutos tratados com $\mathrm{CaC}_{2}$ quanto com etileno, a evolução das médias das características avaliadas ocorreu de forma semelhante ao observado nos frutos não-tratados, porém de forma antecipada e com taxas mais elevadas. Entretanto, nos frutos nãotratados, para várias características, as transformações ocorreram de forma incompleta até o final do período avaliado. Isso confirma a eficiência dos dois produtos em antecipar e uniformizar o amadurecimento da manga 'Ubá'.

Segundo CHITARRA \& CHITARRA(2005), o climatério é tido como uma indicação do final de um período de síntese ativa e manutenção dos processos metabólicos e do início da senescência do fruto. Entretanto, os resultados obtidos neste trabalho não confirmam essa hipótese, pois, para as doses mais elevadas de $\mathrm{CaC}_{2}$ e etileno, o pico climatérico da respiração ocorreu no terceiro dia após os tratamentos, enquanto as características ideais de consumo só foram atingidas por volta do nono dia.

Nota-se que houve efeito de doses dos produtos testados para as características produção de $\mathrm{CO}_{2}$ (Figura 1A e 1B), perda de massa fresca (Figura $1 \mathrm{C}$ e 1D), coloração da casca (Figura 2A e 2B), extravasamento de solutos (Figura 2E e 2F) e SS (Figura 3E e 3F), ou seja, nas maiores doses, a antecipação do amadurecimento foi mais rápida $\mathrm{e}$, para as menores doses, essa antecipação foi mais lenta, não comprometendo o aspecto visual dos frutos ao final do período de avaliação. Portanto, o uso de diferentes doses de $\mathrm{CaC}_{2}$ ou etileno torna-se uma opção para pequenos produtores que comercializam suas frutas em feiras livres e para a indústria, para não haver sobrecarga de trabalho no processamento da fruta.

\section{CONCLUSÃO}

Mangas 'Ubá' tratadas com diferentes doses de etileno e carbureto de cálcio tiveram o seu amadurecimento antecipado e uniformizado, sem comprometer suas características físicas, fisiológicas e bioquímicas. Assim, as menores doses tanto de etileno $\left(50 \mathrm{~mL} \mathrm{~m}^{-3}\right)$ como de carbureto de cálcio $\left(20 \mathrm{~g} \mathrm{~m}^{-3}\right)$ foram suficientes para antecipar e uniformizar o amadurecimento dos frutos e, somente após 15 dias de armazenamento, os frutos do tratamento controle encontravam-se totalmente maduros para consumo in natura, enquanto, para as maiores doses de $\mathrm{CaC}_{2} \mathrm{e}$ etileno, isso ocorreu no nono dia de armazenamento.

\section{REFERÊNCIAS}

BRAZ, V.B. et al. Indução do amadurecimento de mangas cv. Tommy Atkins e cv. Ubá pela aplicação de ethephon pós-colheita. Bragantia, v.67, n.1, p.225-232, 2008. Disponível em: <http:/ /www.scielo.br/pdf/brag/v67n1/a27v67n1.pdf >. Acesso em: 28 mar. 2011. doi: 10.1590/S0006-87052008000100027.

CHITARRA, M.I.F.; CHITARRA, A.B. Pós-colheita de frutas e hortaliças: fisiologia e manuseio. 2.ed. rev. e ampl. Lavras: UFLA, 2005. 785p.

FIORAVANÇO, J.C et al. Ethephon na antecipação da colheita e qualidade da ameixa cv. Reubennel. Scientia Agraria, v.8, n.2, p.193-197, 2007. Disponível em: <http://ojs.c3sl.ufpr.br/ ojs2/index.php/agraria/article/view/8371/6651>. Acesso em: 28 mar. 2011.

HOJO, E. T. D. et al. Uso de tratamento hidrotérmico e ácido clorídrico na qualidade de lichia 'Bengal'. Revista Brasileira de Fruticultura, v.33, n.2, p.386-393, 2011. Disponível em: $<$ http://www.scielo.br/pdf/rbf/v33n2/AOP04411.pdf $>$. Acesso em: 18 nov. 2011. doi: 10.1590/S0100-29452011005000057.

MENDONÇA, V. et al. Utilização do paclobutrazol, ethephon e nitrato de potássio na indução floral da mangueira no semiárido nordestino. Ciência e Agrotecnologia, v.27, n.6, p.1285-1292, 2003. Disponível em: <http://www.scielo.br/ s c i e lo.ph p s cript =s ci_arttext \& pid=S 1413 $70542003000600012 \& \operatorname{lng}=\mathrm{pt} \& \overline{\mathrm{n}} \mathrm{rm}=\mathrm{isso} \& \mathrm{t} \operatorname{lng}=\mathrm{pt}>$. Acesso em: 10 out. 2011. doi: 10.1590/S1413-70542003000600012.

NOGUEIRA, D.H. et al. Mudanças fisiológicas e químicas em bananas 'Nanica' e 'Pacovan' tratadas com carbureto de cálcio. Revista Brasileira de Fruticultura, v.29, n.3, p.460-464, 2007. Disponível em: <http://www.scielo.br/pdf/rbf/v29n3/ a11v29n3.pdf>. Acesso em: 28 mar. 2011. doi: 10.1590/ S0100-29452007000300011

PAL, R.K. Ripening and rheological properties of mango as influenced by ethrel and calcium carbide. Journal of Food Science and Technology, v.35, n.4, p.358-360, 1998.

ROCHA, A. et al. Genetic diversity of 'Ubá Mango tree using ISSR markers. Molecular Biotechnology, v.48, p.200-205, 2011. Disponível em: <http://www.springerlink.com /content/ v8251570tuxg65t4/>. Acesso em: 17 out. 2011. doi: 10.1007/ s12033-011-9419-1. 
SANTOS, V.R et al. Influência do etileno e do 1-MCP na senescência e longevidade das inflorescências de esporinha. Bragantia, v.64, n.1, p.33-38, 2005. Disponível em: <http:/ /www.scielo.br/pdf/brag/v64n1/23850.pdf >. Acesso em: 28 mar. 2011. doi: $10.1590 / \mathrm{S} 0006-87052005000100004$.

SEREK, M. et al. Inhibition of ethylene-induced cellular senescence symptoms by 1-methylcyclopropene, a new inhibitor of ethylene action. Physiologia Plantarum, v.94, p.229232, 1995.

SILVA, D.F.P. et al. Antecipation of 'ubá' mango ripening with preharvest ethephon application. Ciência Rural, v.41, n.1, p.63-69, 2011. Disponível em: <http://www.scielo.br/pdf/cr/ v41n1/a832cr2830.pdf>. Acesso em: 04 mar. 2011. doi: 10.1590/S0103-84782011000100011.

SILVA, D.F.P. et al. Potassium permanganate effects in postharvest conservation of the papaya cultivar 'Sunrise Golden'. Pesquisa Agropecuária Brasileira, v.44, p.669675, 2009a. Disponível em: <http://www.scielo.br/pdf/pab/ v44n7/03.pdf>. Acesso em: 04 mar. 2011. doi: 10.1590/S0100204X2009000700003.

SILVA, D.F.P. et al. Caracterização de frutos de 15 cultivares de mangueira. Revista Ceres, v.56, p.783-789, 2009b. Disponível em: <http://www.ceres.ufv.br/ceres/revistas/V56N006P03809.pdf>. Acesso em: 04 mar. 2011.

STEFFENS, C.A. et al. Maturação da maçã 'Gala' com a aplicação pré-colheita de aminoetoxivinilglicina e ethephon. Ciência Rural, v.36, n.2, p.434-440, 2006. Disponível em: $<$ http://www.scielo.br/pdf/cr/v36n2/a12v36n2.pdf >. Acesso em: 28 mar. 2011. doi: 10.1590/S0103-84782006000200012.

TAIZ, L.; ZEIGER, E. Plant physiology. Trad. Santarén. 3.ed. Porto Alegre: Artmed, 2006. 719p.

ZEITSCHRIFTEN, W. Effects of calcium carbide and 2chloroethylphosphonic acid on fruit quality of thai mangoes under various postharvest ripening regimes. European Journal of Horticultural Science, v.36, p.411-418, 2009. 